\title{
What Factors Influence Users to Install a Photography- Category Application to their Android Smartphone
}

\author{
https://doi.org/10.3991/ijim.v13i02.6726 \\ Rizdania Dermawi $\left.^{(}\right)$, Herman Tolle \\ Universitas Brawijaya, Malang, Indonesia \\ rizdaniadermawi@gmail.com
}

\begin{abstract}
Availability of the various kinds of Android applications provide the users to get any mobile application that can support their daily activities, whether it supports the work or other needs. Too many applications available often confuse the user to make a decision which application they have to install to their smartphone. By using the exploratory factor analysis (EFA), this study analyzes the factors that may influence users to decide whether or not installing a particular application from the photography category in Playstore. The result obtained three main factors, with most variables, interpret the factor is an external factor. The main factors are labeled as Advertisement factor, Application Overview factor, and Users' Side factor. This paper finds that psychologically users consider third party references to discover the satisfaction of photography application functionality.
\end{abstract}

Keywords - Exploratory Factor Analysis (EFA), Google Play store, installation decision, photography applications

\section{Introduction}

Most of the people nowadays are relied on their smartphone, not just for communication but also as a helping tool in their everyday tasks. The smartphone technology development widely increases as the various supported application development also rapidly spreads to support the users' needs.

There are ways to get the mobile apps installed in Android smartphone. Some users ask for their apps to be installed directly from the outlet they bought the phone from. Usually, there are outlets provide that kind of services to ordinary people that are unfamiliar with application installation. However, every Android smartphone users are always being suggested to install any application directly from Google play store, the official application provider for the Android platform, for the sake of security [1].

Today, more than two million Android apps are available at Google play store, consist of various categories that users can pick to install to their Android smartphone. Among those apps, $12 \%$ belongs to low-quality apps. The latest data shows that the most downloaded applications from all apps are from the category of education as 243,794 . The most downloaded free apps are also from the education category as 
225,054, and the most downloaded paid apps are from the category of personalization as 19,947 [2].

The top chart in Google Play Store (by August 20th, 2018) shows that the top categories are Photography, then followed by categories Family, Provider's Recommendation, Music \& Audio, Entertainment, Shopping, Personalization, Social, and Communication. Total applications in Photography category are 70,310, with 4.08 of average rating and $12 \%$ apps with more than fifty thousand downloads [2].

With so many application available in the Photography category, users sometimes are hesitated when they want to choose proper applications. Many elements may affect the user when they are about to install a particular application. This research will evaluate those elements' effect regarding a user's decision to install an application of photography category application. The result of our study is expected to be useful to the developers when they are going to create photography category application that will be downloaded by many users.

This paper will be organized as follows. Section 1 represents an overview and background of the research. Section 2 provides related works correspond to our research. Section 3 will describe the conceptual model. Section 4 will explain the exploratory factor analysis as our research methodology, and the conclusions of possible future work and research issues will be provided in section 5 .

\section{Related Work}

Smartphone application implies as a program which has been intended to be worked in the smartphone and installed by downloading from a particular place [3]. Mobile applications are software applications that designed to run on smartphones, tablets and other mobile devices. Those apps are typically available through app stores which are operated by the owners of the mobile operating system. One of the most popular operating system native stores is Google Play [4].

Android is a mobile operating system (OS) developed by Google. Google bought the company in 2005 and launched the mobile Android OS to the consumer market in 2007. After the Android OS had been launched to the market, it achieved the support of some smartphone manufacturers, which have all built phones explicitly designed for the Android system. The Android increasing popularity devices has a direct impact on the Google play store, which was first introduced as an Android Market [4]. Google play store is now the biggest app store in the world and has more than two million apps available for download [2].

Some studies also have a similar purpose as ours. Some factors that considered to affect in organizational performance are perceived usefulness, user satisfaction, technological, organizational, and people characteristics [5].

Research that evaluated the usability performance of a specific mobile application that focuses on a system for the culinary recommendation consisted of effectiveness, satisfaction and learnability performance [6]. 


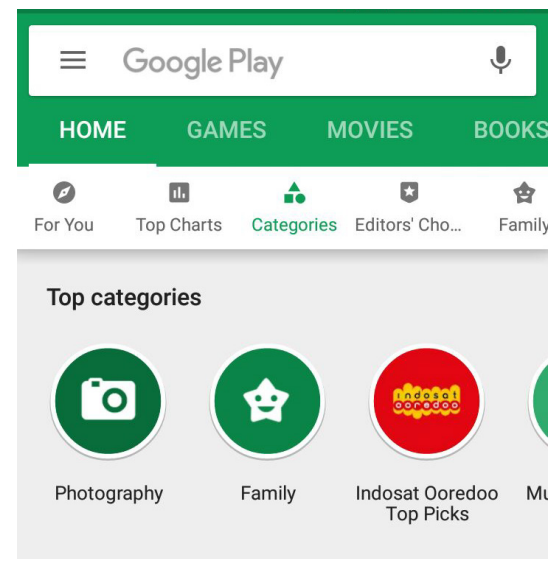

Fig. 1. Top Categories in Google Play Store

Risk perception, privacy concern, and social influence are some elements that may affect the Geo-Social Networks usage, a study that has been conducted by [7].

When users go to Google Play Store, they may find that the apps provided are divided into some categories. In the top categories, Photography is the category that came first, followed by other categories, as shown in Fehler! Verweisquelle konnte nicht gefunden werden. [8]. Some elements that may affect users' decision in installing application are described as following.

\section{$2.1 \quad$ Internal Factors}

Internal factors are all the things that come from the users' side that make them decide to install the Android photography category applications.

Self's Factor: Self's factor consists of two kinds of things, which will be explained in the following:

User's Internet Quota: If users operate their smartphone regarding those connect with mobile data, they may need connectivity to $\mathrm{Wi}-\mathrm{Fi}$, or they have to buy their internet quota from network provider when Wi-Fi does not exist. When users are intended to install particular applications, they may download it from the Google play store, which they have to be connected to the internet.

User's Psychological Trust: As previously mentioned, users are always suggested to go to Play Store whenever they need a particular application, which they can directly download any preferable applications. However, users have many kinds of backgrounds, some are familiar with the technology, but a lot of them are not. Therefore, when they want to have an application installed on their smartphone, the only just go to some outlets that serve the installation for mobile phone.

User's Smartphone Specification: The specification of the smartphone also affects the kind of applications installed. The smartphone specifications such as the internal memory or the camera resolution can be the factor that affects the users whether they decide to install the application or not. 
Apps' Factor: Apps' factors are from all the factor that comes from the particular applications. In this study, we divide this factor into:

Functionality: In information technology, functionality is any aspect of a product or result, for instance, a software application or computing device ability, that is needed by the user [9].

The application fulfills the requirements; the ease of use, if the app was difficult to set up, includes documentation providing clear adequate instructions; application or component functionality works as we assume it was intended; all features work as expected [10].

In the photography category, applications are meant to be functioning for sharing, or editing, or capturing the photo or video.

Free / Paid: There are 2,258 paid applications of 51,154 application in Photography category in Google play store, and the rest are free. This study may evaluate how much this factor will influence users' decision.

\subsection{External Factors}

On the contrary, to the internal factors, external factors are the elements that come from outside of the users' side.

Internal Apps: These factors are the elements that are provided by the application itself. In the Google play store, the items appear along with installation view. The result of this study may be able to recognize how these factors may influence the users in installing the photography category application.

Review: Apps review is an evaluation of an application that comes from the users. It can be either the opinions or suggestions from the users of the application [11].

Rating: Rating is the evaluation or assessment of the application, regarding quality, quantity, or combination of both. In Play Store, the users give the rating in the form of 1-star to 5-stars [11].

Other Influence: Other factors remaining in external factors are advertisement and friends' recommendation.

Advertisement: This factor is the form of marketing communication regarding the specific application. The advertisement can run on television, website or other apps.

We may be able to determine how much the advertisements affect the user to install the apps.

Friends' Recommendation: The last factor used in this research is friends' recommendation. People usually follow for installing a specific application according to their group or community.

\section{Conceptual Model}

The conceptual model is based on the elements that have been described in the previous section. In the model, there will be some modifications for adjusting to the photography category applications in the Google Play store [12]. 
Based on the description in the previous section, the elements/factors that may affect the user to install the photography category applications can be described in the following Fehler! Verweisquelle konnte nicht gefunden werden..

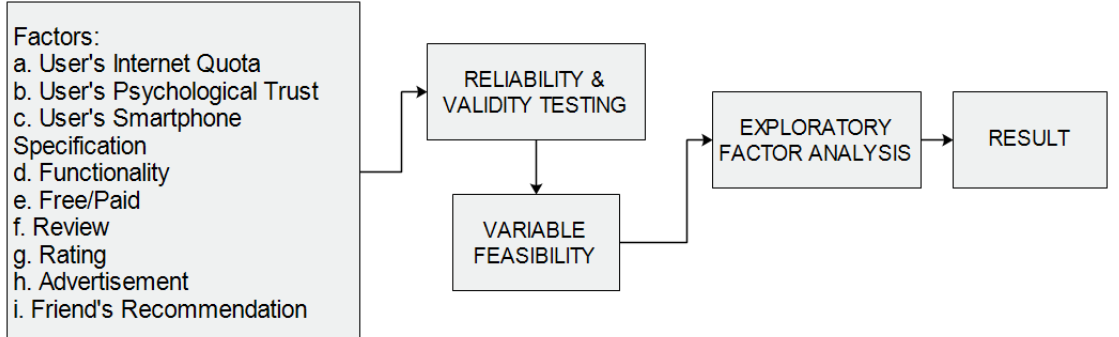

Fig. 2. Conceptual Model

\section{Exploratory Factor Analysis (EFA)}

\subsection{Research Design}

This research can be classified as exploratory research. The exploratory research aims to search new relationships to formulate the research problem. It also studies to define the structure between inspected variables, whether its form a group or it stands by itself [13]. The examination of the factors influence the users to install the mobile photography application is the primary objective of our study. From Figure 1, there are sixteen variables formed and will be analyzed in the study. Those variables are the number of the questionnaires for the respondents. The indicators then will be rated with five Likert scales ranging from level 1 ("never") to level 5 ("always"). The statements in our questionnaire represent every indicator. We also ask the respondents to fill out some demographic information such as age and occupation. The respondents are the users that have been familiar with the use of photography category application; those are for sharing, editing, or capturing the photo or video.

\subsection{Respondent Demographics}

The total of valid questionnaires is from 79 respondents, which are the users of photography category application from age 15 to 45 years old. The number of male and female respondents are considered equal. Some of the respondents are familiar with using more than one kind of photography category application. Fehler! Verweisquelle konnte nicht gefunden werden. shows the chart of respondent demographics.

\subsection{Data Analysis}

Validity and Reliability Testing: This study evaluated the data using the Exploratory Factor Analysis (EFA), which is a statistical method area to reveal the basic 
structure of data. It can be used for refinement steps, construction validity evaluation and also hypothesis testing [14].

This approach is usually taken for multivariate statistical cases in education, psychology and also professions related to health. In EFA, the researchers have no expectations of some variables. So the investigators are allowed to explore for generating a theory, or model from the proposed model [15].

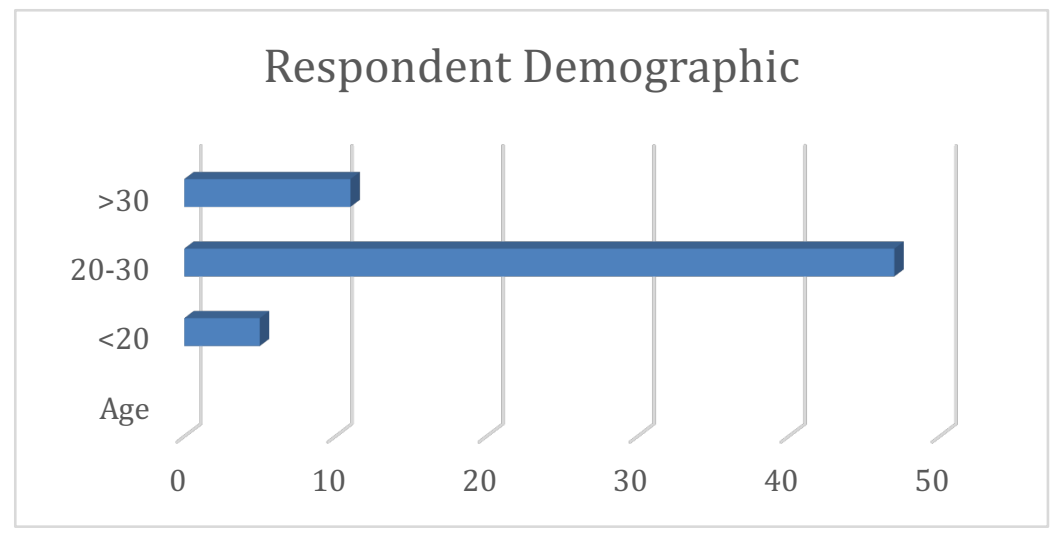

Fig. 3. Respondent Demographics

Just like the previous research, several processes are sequentially performed to obtain the value from the result of distributed questionnaires [16].

Most often reported the type of reliability coefficient is coefficient alpha that usually called Cronbach's alpha. The evaluation calculates the internal consistency reliability. When the internal consistency occurs low, then the item content means very varied, so the total score is not the best analysis for the calculation [17].

Table 1. The value obtained from the first testing result

\begin{tabular}{|l|c|c|c|c|}
\hline \multicolumn{1}{|c|}{ Factor } & $\begin{array}{c}\text { Scale Mean if Item } \\
\text { Deleted }\end{array}$ & $\begin{array}{c}\text { Scale Variance if } \\
\text { Item Deleted }\end{array}$ & $\begin{array}{c}\text { Corrected Item- } \\
\text { Total Correlation }\end{array}$ & $\begin{array}{c}\text { Cronbach's Alpha } \\
\text { if Item Deleted }\end{array}$ \\
\hline Fnc1 & 54.8228 & 80.814 & .398 & .750 \\
\hline Fnc2 & 54.0253 & 83.692 & .256 & .760 \\
\hline Fnc3 & 54.6076 & 75.318 & .544 & .736 \\
\hline UIQ1 & 54.8481 & 83.643 & .156 & .772 \\
\hline UIQ2 & 54.2911 & 78.209 & .391 & .750 \\
\hline UPT1 & 56.1013 & 83.605 & .278 & .759 \\
\hline UPT2 & 53.4177 & 81.067 & .433 & .748 \\
\hline USS1 & 55.1013 & 79.836 & .379 & .751 \\
\hline USS2 & 55.2152 & 81.094 & .276 & .760 \\
\hline FP1 & 53.3418 & 83.382 & .303 & .757 \\
\hline FP2 & 53.7722 & 80.255 & .376 & .751 \\
\hline FP3 & 55.0127 & 86.115 & .055 & .782 \\
\hline Rv1 & 53.7848 & 80.325 & .450 & .747 \\
\hline
\end{tabular}




\begin{tabular}{|l|c|c|c|c|}
\hline Rt1 & 53.8608 & 81.506 & .406 & .750 \\
\hline Adv1 & 55.0886 & 80.800 & .421 & .749 \\
\hline Adv2 & 55.0253 & 80.128 & .458 & .746 \\
\hline Adv3 & 55.2785 & 80.973 & .418 & .749 \\
\hline FR1 & 54.1013 & 83.605 & .372 & .754 \\
\hline
\end{tabular}

Table 2. Value Obtained From the Second Testing Result

\begin{tabular}{|l|c|c|c|c|}
\hline \multicolumn{1}{|c|}{ Factor } & $\begin{array}{c}\text { Scale Mean if } \\
\text { Item Deleted }\end{array}$ & $\begin{array}{c}\text { Scale Variance if } \\
\text { Item Deleted }\end{array}$ & $\begin{array}{c}\text { Corrected Item-Total } \\
\text { Correlation }\end{array}$ & $\begin{array}{c}\text { Cronbach's Alpha if } \\
\text { Item Deleted }\end{array}$ \\
\hline Fnc1 & 41.2911 & 53.055 & .381 & .780 \\
\hline Fnc3 & 41.0759 & 47.122 & .616 & .755 \\
\hline UIQ2 & 40.7595 & 50.313 & .405 & .780 \\
\hline UPT2 & 39.8861 & 52.538 & .470 & .773 \\
\hline USS1 & 41.5696 & 54.274 & .246 & .794 \\
\hline FP1 & 39.8101 & 53.925 & .371 & .781 \\
\hline FP2 & 40.2405 & 51.749 & .410 & .778 \\
\hline Rv1 & 40.2532 & 52.217 & .465 & .773 \\
\hline Rt1 & 40.3291 & 52.942 & .438 & .775 \\
\hline Adv1 & 41.5570 & 52.840 & .419 & .777 \\
\hline Adv2 & 41.4937 & 51.689 & .499 & .770 \\
\hline Adv3 & 41.7468 & 52.679 & .437 & .775 \\
\hline FR1 & 40.5696 & 55.710 & .324 & .784 \\
\hline
\end{tabular}

EFA process uses a correlation matrix to display the relationships between individual variables. The correlation matrix has to be over 0.30 , which means that within the data the factor accounts for approximately $30 \%$ relationship [15].

This study examines the Cronbach's Alpha to test the reliability testing, for complete obtained data for first testing which is 0.756 .18 factors are being calculated using SPSS as the tool for the statistics; the first testing result is shown in Fehler! Verweisquelle konnte nicht gefunden werden.

Table 3. Value Obtained From the Third Testing Result

\begin{tabular}{|c|c|c|c|c|}
\hline Factor & $\begin{array}{c}\text { Scale Mean if } \\
\text { Item Deleted }\end{array}$ & $\begin{array}{c}\text { Scale Variance if } \\
\text { Item Deleted }\end{array}$ & $\begin{array}{c}\text { Corrected Item-Total } \\
\text { Correlation }\end{array}$ & $\begin{array}{c}\text { Cronbach's Alpha if } \\
\text { Item Deleted }\end{array}$ \\
\hline Fnc1 & 38.6456 & 47.565 & .359 & .787 \\
\hline Fnc3 & 38.4304 & 41.941 & .597 & .761 \\
\hline UIQ2 & 38.1139 & 44.564 & .409 & .785 \\
\hline UPT2 & 37.2405 & 46.441 & .495 & .775 \\
\hline FP1 & 37.1646 & 47.755 & .396 & .783 \\
\hline FP2 & 37.5949 & 46.065 & .406 & .783 \\
\hline Rv1 & 37.6076 & 46.421 & .469 & .777 \\
\hline Rt1 & 37.6835 & 46.937 & .455 & .778 \\
\hline Adv1 & 38.9114 & 47.031 & .421 & .774 \\
\hline Adv2 & 38.8481 & 45.951 & .500 & .781 \\
\hline Adv3 & 39.1013 & 47.041 & .427 & \\
\hline
\end{tabular}




\begin{tabular}{l|l|l|l|l} 
FR1 & 37.9241 & 49.789 & .323 & .789
\end{tabular}

The first testing result obtained that there are some factors with corrected item-total correlation with values above 0.3 and the values below it (which is blocked in green). Those factors are Fnc2 with a value of 0.256 , UIQ1 with a value of 0.156 , UPT1 with a value of 0.278 , USS2 with a value of 0.276 and FP4 with a value of 0.055 . The factors with a value less than 0.3 are removed than we recalculate the validity and reliability test using SPSS.

The second testing with only 13 factors resulted in the Cronbach's Alpha value is 0.790 . Just like the first testing, the obtained corrected item-total correlation is also examined in the second testing. The factor with a value less than 0.3 is USS1 (0.246). The value obtained interpret the second testing result is shown in Fehler! Verweisquelle konnte nicht gefunden werden.

The third testing was calculated (with the rest 12 indicators/factors), it resulted the Cronbach's Alpha value is 0.794 . In third testing, all value of corrected item-total correlation obtained above 0.3 , we can say that all indicators/factors are valid and reliable. The value obtained interpret the second testing result is shown in Fehler! Verweisquelle konnte nicht gefunden werden.

Kaiser-Meyer-Olkin (KMO) and Bartlett's Test: To examine the adequacy of the samples suitability testing of the observation number (data) and the multivariant correlation was being examined using Kaiser-Myer-Olkin (KMO) and Barlett test. The result is shown in Fehler! Verweisquelle konnte nicht gefunden werden..

KMO value of 0.662 which is more significant than 0.5 , it means the first requirement that is the adequacy of the data is being fulfilled. The Sig. The value of Barlett's Test of Sphericity is 0.000 which is smaller than Alpha 0.05 ; it means that this factor analysis is feasible. The conclusion can be considered as there is a correlation between all the multivariate variable.

Eigenvalue: Eigenvalue represents the sum of squared loadings for a factor. It is frequently used to determine the number of factors. According to Kaiser criterion as a way to decide the constructs number for rotation (factors with eigenvalues higher than one). Another method used to determine the number of factors is Scree test as the representation of the eigenvalues [13].

By using SPSS tool,

\begin{tabular}{|l|c|}
\hline \multicolumn{1}{|c|}{ Kaiser-Meyer-Olkin Measure of Sampling Adequacy. } & .662 \\
\hline Approx. Chi-Square & 327.86 \\
\hline Bartlett's Test of Sphericity & 4 \\
\hline df & 66 \\
\hline Sig. & .000 \\
\hline
\end{tabular}

Component Matrix: The eigenvalues obtained some factors, which are three factors. Moreover, also by using SPSS tool, with principal component analysis extraction method, we get Matrix Rotation: The purpose of rotation is to make the group of factors simplified, it minimizes low factor loadings and maximizes high factor loadings that are greater than 0.55 [15]. Based on Fehler! Verweisquelle konnte nicht gefunden werden., variable Adv2 has the greatest loading factor in factor 1 that is 0.899 , but this variable has low loading factor in factor 2 and factor 3, so variable Adv2 in included in factor 1 . 
Fehler! Verweisquelle konnte nicht gefunden werden. shows the result of the rotated component matrix obtained in SPSS tool, using Varimax with Kaiser Normalization. The first factor consists of variables Adv1, Adv2, and Adv3. The second factor consists of variables Rv1 and Rt1, and the last factor consists of variables UPT1, FP1, and FP2.

of Component Matrix which shows the distribution of 12 variables in 3 factors formed. The values in the table are factor loadings that show a correlation between the variable itself to factor number 1 , number 2 and number 3 . The variable determination process for which factor is by comparing the correlation value in each row of the variable.

shows the result of some factors based on eigenvalue, that is larger than 1 . There are only three factors that have eigenvalue more significant than 1 . The result can also be seen in Fehler! Verweisquelle konnte nicht gefunden werden..

Table 4. KMO and Bartlett's Test

\begin{tabular}{|l|c|}
\hline Kaiser-Meyer-Olkin Measure of Sampling Adequacy. & .662 \\
\hline Approx. Chi-Square & 327.86 \\
\hline Bartlett's Test of Sphericity & 4 \\
\hline df & 66 \\
\hline Sig. & .000 \\
\hline
\end{tabular}

Component Matrix: The eigenvalues obtained some factors, which are three factors. Moreover, also by using SPSS tool, with principal component analysis extraction method, we get Matrix Rotation: The purpose of rotation is to make the group of factors simplified, it minimizes low factor loadings and maximizes high factor loadings that are greater than 0.55 [15]. Based on Fehler! Verweisquelle konnte nicht gefunden werden., variable Adv2 has the greatest loading factor in factor 1 that is 0.899 , but this variable has low loading factor in factor 2 and factor 3, so variable Adv2 in included in factor 1 .

Fehler! Verweisquelle konnte nicht gefunden werden. shows the result of the rotated component matrix obtained in SPSS tool, using Varimax with Kaiser Normalization. The first factor consists of variables Adv1, Adv2, and Adv3. The second factor consists of variables Rv1 and Rt1, and the last factor consists of variables UPT1, FP1, and FP2.

of Component Matrix which shows the distribution of 12 variables in 3 factors formed. The values in the table are factor loadings that show a correlation between the variable itself to factor number 1 , number 2 and number 3 . The variable determination process for which factor is by comparing the correlation value in each row of the variable.

Table 5. Number of factors based on eigenvalue

\begin{tabular}{|l|c|c|c|}
\hline \multirow{2}{*}{ Component } & \multicolumn{3}{|c|}{ Initial Eigenvalues } \\
\cline { 2 - 4 } & Total & \% of Variance & Cumulative \% \\
\hline 1 & 3.741 & 31.173 & 31.173 \\
\hline 2 & 2.046 & 17.047 & 48.220 \\
\hline 3 & 1.139 & 9.489 & 57.709 \\
\hline 4 & .965 & 8.042 & 65.752 \\
\hline 5 & .920 & 7.670 & 73.422 \\
\hline
\end{tabular}




\begin{tabular}{|l|l|l|l|}
\hline 6 & .800 & 6.669 & 80.091 \\
\hline 7 & .730 & 6.080 & 86.171 \\
\hline 8 & .557 & 4.646 & 90.817 \\
\hline 9 & .407 & 3.390 & 94.206 \\
\hline 10 & .314 & 2.616 & 96.822 \\
\hline 11 & .225 & 1.873 & 98.695 \\
\hline 12 & .157 & 1.305 & 100.000 \\
\hline
\end{tabular}

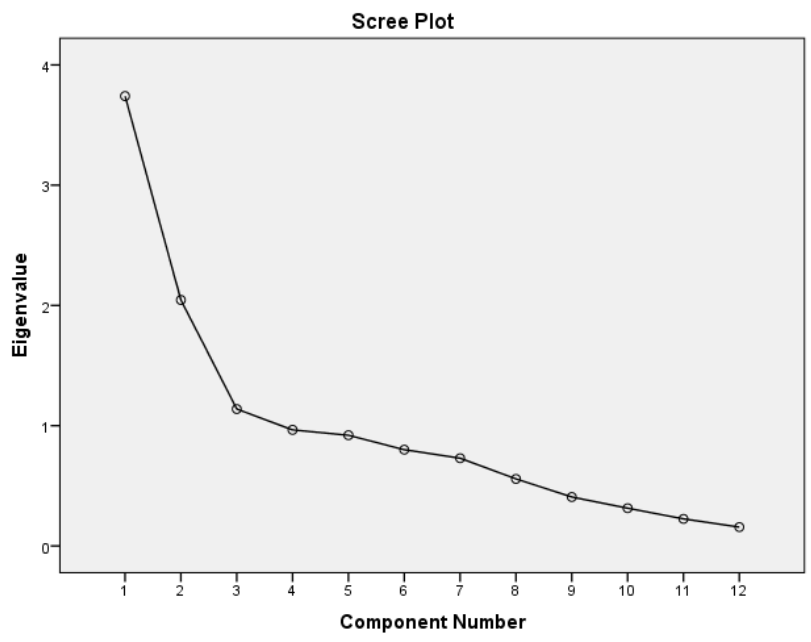

Fig. 4. Scree Plot of the Eigenvalues

Matrix Rotation: The purpose of rotation is to make the group of factors simplified, it minimizes low factor loadings and maximizes high factor loadings that are greater than 0.55 [15]. Based on Fehler! Verweisquelle konnte nicht gefunden werden., variable Adv2 has the greatest loading factor in factor 1 that is 0.899 , but this variable has low loading factor in factor 2 and factor 3, so variable Adv2 in included in factor 1.

Fehler! Verweisquelle konnte nicht gefunden werden. shows the result of the rotated component matrix obtained in SPSS tool, using Varimax with Kaiser Normalization. The first factor consists of variables Adv1, Adv2, and Adv3. The second factor consists of variables Rv1 and Rt1, and the last factor consists of variables UPT1, FP1, and FP2.

Table 6. Component Matrix

\begin{tabular}{|l|c|c|c|}
\hline \multirow{2}{*}{} & \multicolumn{3}{|c|}{ Component } \\
\cline { 2 - 4 } & $\mathbf{1}$ & $\mathbf{2}$ & $\mathbf{3}$ \\
\hline Fnc1 & .476 & -.028 & -.196 \\
\hline Fnc3 & .712 & .117 & -.077 \\
\hline UIQ2 & .522 & -.069 & .341 \\
\hline UPT2 & .606 & .449 & .125 \\
\hline FP1 & .508 & .616 & .348 \\
\hline
\end{tabular}


Paper-What factors influence users to install a Photography-Category Application ...

\begin{tabular}{|l|l|l|l|}
\hline FP2 & .505 & .321 & .473 \\
\hline Rv1 & .604 & .227 & -.464 \\
\hline Rt1 & .575 & .034 & -.561 \\
\hline Adv1 & .536 & -.682 & .099 \\
\hline Adv2 & .614 & -.663 & .110 \\
\hline Adv3 & .558 & -.534 & .108 \\
\hline RC1 & .427 & .314 & -.233 \\
\hline
\end{tabular}

Table 7. Rotated Component Matrix

\begin{tabular}{|l|c|c|c|}
\hline & \multicolumn{3}{|c|}{ Component } \\
\cline { 2 - 4 } & $\mathbf{1}$ & $\mathbf{2}$ & $\mathbf{3}$ \\
\hline Fnc1 & .248 & .437 & .115 \\
\hline Fnc3 & .292 & .533 & .398 \\
\hline UIQ2 & .423 & .058 & .460 \\
\hline UPT2 & .011 & .397 & .654 \\
\hline FP1 & -.130 & .212 & .835 \\
\hline FP2 & .131 & .045 & .750 \\
\hline Rv1 & .060 & .777 & .154 \\
\hline Rt1 & .176 & .784 & -.030 \\
\hline Adv1 & .867 & .097 & -.026 \\
\hline Adv2 & .899 & .143 & .034 \\
\hline Adv3 & .764 & .140 & .073 \\
\hline RC1 & -.060 & .516 & .254 \\
\hline
\end{tabular}

Table 8. Total Variance Explained

\begin{tabular}{|l|c|c|c|c|c|c|}
\hline \multirow{2}{*}{ Component } & \multicolumn{3}{|c|}{ Initial Eigenvalues } & \multicolumn{2}{c|}{ Extraction Sums of Squared Loadings } \\
\cline { 2 - 7 } & Total & $\begin{array}{c}\text { \% of } \\
\text { Variance }\end{array}$ & Cumulative \% & Total & $\begin{array}{c}\text { \% of } \\
\text { Variance }\end{array}$ & Cumulative \% \\
\hline 1 & 3.741 & 31.173 & 31.173 & 3.741 & 31.173 & 31.173 \\
\hline 2 & 2.046 & 17.047 & 48.220 & 2.046 & 17.047 & 48.220 \\
\hline 3 & 1.139 & 9.489 & 57.709 & 1.139 & 9.489 & 57.709 \\
\hline 4 & .965 & 8.042 & 65.752 & & & \\
\hline 5 & .920 & 7.670 & 73.422 & & & \\
\hline 6 & .800 & 6.669 & 80.091 & & & \\
\hline 7 & .730 & 6.080 & 86.171 & & & \\
\hline 8 & .557 & 4.646 & 90.817 & & & \\
\hline 9 & .407 & 3.390 & 94.206 & & & \\
\hline 10 & .314 & 2.616 & 96.822 & & & \\
\hline 11 & .225 & 1.873 & 98.695 & & & \\
\hline 12 & .157 & 1.305 & 100.000 & & & \\
\hline
\end{tabular}

Rotation Method: Varimax with Kaiser Normalization 


\section{$5 \quad$ Result and Analysis}

From all the processes described in previous sections, in this section there will be an interpretation phase for the result obtained by naming the factors according to the characteristic of the factor. The first factor that consists of variables Adv1, Adv2 and Adv3 are labeled Advertisement factor. The second factor consists of variables Rv1 (review) and Rt1 (rating), so these factors are labeled as Application Overview factor. The third factor consists of variables UPT2 (user's psychological trust), FP1 and FP2 (for free/paid application) which the users prefer to choose free applications, so the factor is labeled as User's Side. Fehler! Verweisquelle konnte nicht gefunden werden. shows the total variance explained in our study.

The last phase of exploratory factor analysis is stability and consistency testing of a formed factor. First criteria used is an eigenvalue. The eigenvalue that is greater than one is in factor 1 , factor 2 and factor 3 . The second criteria used is based on the scree plot in Fehler! Verweisquelle konnte nicht gefunden werden.. From the combination of the criteria, we may conclude that there are three factors formed.

By using exploratory factor analysis, this study has reached three factors that influence the user to install photography application on their Android smartphone, the factors are:

\subsection{Factor 1 labeled as Advertisement factor}

The first factor is formed by three variables that are: advertisement of the application running on television (Adv1), internet/web (Adv2), and other application (Adv3). The highest loading factor is earned by Adv2 (0.899) that is advertisement running on the internet/web. Research by Adology revealed that mobile advertising and mobile application affects users' purchase behavior [18] and also a study of attitudes toward mobile advertising [19].

\subsection{Factor 2 labeled as Application Overview factor}

The second factor is formed by two variables; review of the application (Rv1) and rating of the application (Rt1). Both variables have nearly similar loading factors that are 0.777 and 0.784 . Some sites discuss the importance of application review and rating [20]-[23]. Some studies also have researched about users' review as a source of improving apps for developers [24], and unique study about online review features [25].

\subsection{Factor 3 labeled as User's Side factor}

The third factor is formed of three variables, which are; UPT2 (loading factor: 0.654) that stands for user psychological trust, and FP1 (loading factor: 0.835) and FP2 (loading factor: 0.750) that stand for free/paid application. User psychological trust variable represents user's awareness to download the application directly from Google play store. Moreover, it already mentioned in the previous section that for their own 
secure, users are always suggested to install the application directly from Google play store[1], [26].

Free/paid variables represent users' tendency to choose free apps more than paid ones. Some sites discuss the application pricing, monetizing and why most apps are free [27]-[30]. Some studies discussed covert communication in mobile apps [31] and also about the impact of the hidden cost of free mobile apps [32].

\section{Conclusion}

The previous section already discussed the exploratory factor analysis to identify the factors that influence the user to install mobile photography application from Google play store. The variables are chosen by using the Kaiser-Meyer-Olkin (KMO) Measure of Sampling Adequacy and Bartlett's Test of Sphericity. The factor formed by approaching based on eigenvalue and scree plot. The interpretation of factor analysis result is based on factor loading significantly and labeling the factor formed.

The factor analysis resulted in three main factors that influence the user to install a mobile photography application to their Android smartphone. The factors are Advertisement factor, Overview factor, and Users' Side factor. From the description in section two, most of the variables that form the main factor are from external factor (advertisement, review, rating, and free application), except for user psychological trust which is an internal factor. We find that when users want to know about the satisfactory or functionality of a mobile application, they only just follow the third party references which are review and rating of an application.

There is a high expectation that the result of this study may be useful for the developers, especially the mobile photography application for guidance so that the applications developed will be downloaded, successfully installed, and also used by many active users continuously.

In this study, only exploratory factor analysis (EFA) is used as a methodology for obtaining the result to analyze the factors. For the future work and research, it is highly expected that more methodologies will be involved to obtain the result thoroughly.

\section{$7 \quad$ References}

[1] Lily Hay Newman, "Never Ever (Ever) Download Android Apps Outside of Google Play," 2016. [Online]. Available: https://www.wired.com/2016/12/never-ever-ever-downloadandroid-apps-outside-google-play/. [Accessed: 20-Aug-2018].

[2] AppBrain, "www.appbrain.com," 2017. [Online]. Available: https://www.appbrain.co m/stats/number-of-android-apps. [Accessed: 20-Aug-2018].

[3] H. Lee, "A Study on the Factors Affecting Smart Phone Application Acceptance," in 2012 3rd International Conference on e-Education, e-Business, e-Management and e-Learning, IPEDR, 2012, vol. 27, pp. 27-34.

[4] Statista - The Statistics Portal, "Statista - The Statistics Portal," 2016. [Online]. Available: https://www.statista.com/topics/1002/mobile-app-usage/. [Accessed: 20-Aug-2018]. 
[5] Y. H. Al-mamary, A. Shamsuddin, and N. Aziati, "Factors Affecting Successful Adoption of Management Information Systems in Organizations towards Enhancing Organizational Performance,” Am. J. Syst. Softw., vol. 2, no. 5, pp. 121-126, 2014.

[6] H. M. Az-zahra, A. Pinandito, and H. Tolle, "Usability Evaluation of Mobile Application in Culinary Recommendation System," in 2015 IEEE Asia Pasific Conference on WIreless and Mobile, 2015, pp. 89-94. https://doi.org/10.1109/APWiMob.2015.7374938

[7] E. Aïmeur, S. Gambs, and C. Y. Yep, "An Empirical Study on GSN Usage Intention : Factors Influencing the Adoption of Geo-Social Networks," in 11th International Conference on Availability, Reliability and Security, 2016, pp. 241-246. https://doi.org/10.1109/ARES.2016.102

[8] Google, "Google Playstore," Google Playstore, 2018. .

[9] R. Margaret, “TechTarget." [Online]. Available: http://searchmicroservices. techtarget.com/definition/functionality. [Accessed: 20-Aug-2018].

[10] S. Developers, "developer.salesforce.com," 2008. [Online]. Available: https://developer.salesforce.com/page/An_Application_Functionality_Review. [Accessed: 20-Aug-2018].

[11] Wikipedia, "Wikipedia The Free Encyclopedia," 2017. [Online]. Available: https://en.wikipedia.org. [Accessed: 20-Aug-2018].

[12] A. Gie Yong and S. Pearce, "A Beginner's Guide to Factor Analysis: Focusing on Exploratory Factor Analysis," Tutor. Quant. Methods Psychol., vol. 9, no. 2, pp. 79-94, 2013. https://doi.org/10.20982/tqmp.09.2.p079

[13] H. Taherdoost, S. Sahibuddin, and N. Jalaliyoon, "Exploratory factor analysis: Concepts and theory," in 2nd International Conference on Mathematical, Computational and Statistical Sciences, 2014, pp. 375-382.

[14] A. I. H. James M. Conway, "A Review and Evaluation of Exploratory Factor Analysis Practices in Organizational Research," SAGE Journals, vol. 6, no. 2, pp. 147-168, 2003.

[15] B. Williams and T. Brown, "Exploratory Factor Analysis : A Five-step Guide for Novices," J. Emerg. Prim. Heal. Care, vol. 8, no. 3, pp. 1-13, 2012.

[16] L. Fabrigar, D. Wegener, R. MacCallum, and E. Strahan, "Evaluating the use of exploratory factor analysis in psychological research," Pyschological Methods, vol. 4, no. 3, pp. 272290, 1999. https://doi.org/10.1037/1082-989X.4.3.272

[17] R. B. Kline, Principles and Practice of Structural Equation Modeling, vol. 77, no. 27. The Guilford Press, 2011.

[18] G. Tsirulnik, "Smartphone apps and mobile ads influence purchase intent: study," Jan. 11, 2011, 2011. [Online]. Available: http://www.mobilemarketer.com/ex/mobilemarketer/ cms/news/research/8743.html. [Accessed: 20-Aug-2018].

[19] T. D. Le and B. T. H. Nguyen, "Attitudes toward mobile advertising: A study of mobile web display and mobile app display advertising,” Asian Acad. Manag. J., vol. 19, no. 2, pp. 87103, 2014.

[20] A. Nanji, “How Influential Are Mobile App Star Ratings?," May 22, 2015, 2015. [Online]. Available: http://www.marketingprofs.com/charts/2015/27665/how-influential-are-mobileapp-star-ratings. [Accessed: 20-Aug-2018].

[21] M. A. Team, "The Importance of App Ratings and Reviews," October 21. [Online]. Available: https://www.mobileaction.co/blog/importance-ratings-reviews/. [Accessed: 23Mar-2017].

[22] A. SEFFERMAN, "The Average Mobile Apps' Ratings and Reviews, by Category," OCTOBER 20, 2016, 2016. [Online]. Available: https://www.apptentive.com/blog /2016/10/20/average-mobile-apps-ratings-and-reviews-by-category/. [Accessed: 20-Aug2018]. 
[23] I. S. University, "Mobile apps and online reviews influence consumer behavior," September 30, 2015, 2015. [Online]. Available: https://www.sciencedaily.com/ releases/2015/09/150930092506.htm. [Accessed: 20-Aug-2018].

[24] I. J. I. Technology, C. Science, M. Khalid, M. Asif, and U. Shehzaib, "Towards Improving the Quality of Mobile App Reviews,” no. September, pp. 35-41, 2015.

[25] R. Johanes and A. A. Pinem, "What Features of Online Review Affects Reader s' Intention to Travel ?" in ICACSIS 2016, 2016.

[26] G. Support, “Accounts Help." [Online]. Available: https://support.google.com/a ccounts/answer/2812853?hl=en. [Accessed: 23-Mar-2017].

[27] S. Casto, "FREE APPS VS PAID APPS: WHAT BRINGS IN THE BIGGEST PROFIT?" [Online]. Available: http://www.preapps.com/blog/free-apps-vs-paid-apps-what-brings-inthe-biggest-profit. [Accessed: 23-Mar-2017].

[28] M. E. Gordon, "The History of App Pricing, And Why Most Apps Are Free," July 18, 2013, 2013. [Online]. Available: http://flurrymobile.tumblr.com/post/115189750715/the-historyof-app-pricing-and-why-most-apps-are. [Accessed: 23-Mar-2017].

[29] F. Cleary, "Freemium, Paid, or Ad-Supported: Which App Monetization Strategy is Right For You?" [Online]. Available: https://fbombmedia.com/freemium-paid-ad-supported-appmonetization-strategy-right/. [Accessed: 20-Aug-2018].

[30] W. Rhodes, "How Do Free Apps Make Money?," September 2, 2015, 2015. [Online]. Available: https://savvyapps.com/blog/how-do-free-apps-make-money. [Accessed: 20Aug-2018].

[31] J. Rubin, M. I. Gordon, N. Nguyen, and M. Rinard, "Covert Communication in Mobile Applications," ASE '15 (30th IEEE/ACM Int. Conf. Autom. Softw. Eng., 2015. https://doi.org/10.1109/ASE.2015.66

[32] Gui, S. Mcilroy, M. Nagappan, and W. G. J. Halfond, "Truth in advertising: The hidden cost of mobile ads for software developers," in Proceedings - International Conference on Software Engineering, 2015, vol. 1, pp. 100-110.

\section{Authors}

Rizdania is current as a Magister student in Faculty of Computer Science Brawijaya University, Malang, Indonesia. She obtained a Bachelor Degree in Electrical Engineering from Brawijaya University, Malang, Indonesia in 2004. Now she is currently finalizing her Master Degree in Computer Science at Brawijaya University. She is with the Research Group of Multimedia, Game and Mobile Technology, Informatics Department of Computer Science Faculty, Brawijaya University.

Herman Tolle is currently a full-time lecturer in Brawijaya University, Malang Indonesia. He obtained his Bachelor Degree in Electrical Engineering Brawijaya University, Master Degree in Information Systems Telecommunications ITB, Bandung, Indonesia and Doctoral Degree in Information Science, Saga University, Japan. He is with the Research Group of Multimedia, Game and Mobile Technology, Computer Science Faculty, Brawijaya University, Malang, Indonesia.

Article submitted 05 February 2017. Resubmitted 30 August 2018 and 08 January 2019. Final acceptance 08 January 2019. Final version published as submitted by the authors. 